\section{O cotidiano no alojamento materno, das mães de crianças internadas em uma Unidade de Terapia Intensiva Neonatal}

\section{The daily routine of rooming-in mothers whose children are in a Neonatal Intensive Care Unit}

\author{
Erika da Silva Dittz 1 \\ Joaquim Antônio César Mota 2 \\ Roseni Rosângela de Sena 3
}

\author{
1 Faculdade de Medicina. Universidade Federal de Minas Gerais. \\ Av. Alfredo Balena, 190. Belo Horizonte, MG, Brasil. \\ CEP: 30.130-100. E-mail: erikadittz@hotmail.com \\ 2 Departamento de Pediatria. Faculdade de Medicina. Universidade \\ Federal de Minas Gerais. Belo Horizonte, MG, Brasil. \\ 3 Departamento de Enfermagem Materno-Infantil e Saúde Pública. \\ Escola de Enfermagem. Universidade Federal de Minas Gerais. \\ Belo Horizonte, MG, Brasil.
}

Abstract

Objectives: to investigate the daily routine of mothers rooming-in at the Neonatal Intensive Care Unit.

Methods: qualitative research carried out at the Sofia Feldman Hospital in Belo Horizonte, in the State of Minas Gerais, Brazil. The data was obtained by way of participant observation and a focus group and the instruments used to record the data were field diaries, recorders and tapes. Content analysis was used to analyze the data.

Results: when deciding to room in, the mothers feel divided between meeting the needs of the hospitalized child, the demands of the family and their own needs. Living in a hospital environment requires that mothers become detached from her daily routine and adapt to a new pattern which is determined by the institutional routines and norms. Rooming presents mothers with the opportunity to establish relationships of friendship and solidarity, but it is also a time of conflicting relations for them.

Conclusions: the relationships between the mothers, and with their families and health workers were shown to be important for adaptation to the rooming-in process. The study showed the importance for health workers to get more involved in the reallife situation of the mothers in order to facilitate their adaptation to the new daily routine.

Key words Newborn, Neonatal Intensive Care Unit (NICU), Rooming-in care

\section{Resumo}

Objetivos: conhecer o cotidiano no alojamento de mães, cujas crianças estão internadas em uma Unidade de Terapia Intensiva Neonatal.

Métodos: pesquisa qualitativa realizada no Hospital Sofia Feldman, em Belo Horizonte, Minas Gerais, Brasil. Os dados foram obtidos por meio de observação participante e grupo focal, e os instrumentos utilizados para registro dos dados foram os diários de campo, gravadores e fitas. Para análise dos dados utilizou-se a análise de conteúdo.

Resultados: ao decidir permanecer no alojamento materno a mãe se sente dividida entre atender as necessidades do filho hospitalizado, as demandas da família e as suas próprias necessidades. A vivência no ambiente hospitalar exige que a mãe se adapte a uma nova dinâmica, determinada pelas rotinas e normas institucionais. A permanência no alojamento materno, ao mesmo tempo em que surge como uma possibilidade das mães estabelecerem relações de amizade e solidariedade, é um espaço de relações conflituosas entre elas.

Conclusões: na adaptação da mãe ao novo cotidiano, revelou-se importante a convivencia entre as mães, a família e os profissionais de saúde. O estudo aponta para a importância do profissional de saúde aproximar-se da realidade vivenciada pelas mães, para facilitar sua adaptação.

Palavras-chave Recém-nascido, Unidade de Terapia Intensiva Neonatal (UTIN), Alojamento conjunto 


\section{Introdução}

No final da década de 40, alguns pesquisadores alertaram para os prejuízos advindos da separação entre mãe e filho após o nascimento.1,2 Essas descobertas abriram um novo campo de pesquisa que orientam as práticas assistenciais.

Assim, com os avanços proporcionados pelas pesquisas, a busca por uma assistência que favoreça a presença da mãe junto ao filho e a legitimação conferida pelo Estatuto da Criança e do Adolescente, ${ }^{3}$ têm sido criadas estratégias que facilitam a permanência da mãe junto ao recémnascido nas situações em que se fazem necessários os cuidados hospitalares. Nesse sentido, para Scochi4 as práticas neonatais que dificultam o relacionamento entre o bebê e os pais dão lugar àquelas que se preocupam em atender as necessidades psico-biológicas e sociais da criança e da família. Desse modo, o modelo fundamentado na lógica mecanicista - cuja finalidade é a manutenção e a recuperação das condições fisiológicas do bebê - é substituído por um modelo fundamentado no processo saúde-doença-cuidado, que enfatiza a assistência integral, humanizada e preventiva.

Pelo exposto, oferecer um atendimento humanizado em uma Unidade de Terapia Intensiva Neonatal (UTIN), espaço dominado pelos avanços da medicina, implica em utilizar tecnologias que vão além daquelas contidas nos equipamentos. A partir dessa ótica, cuidar da mãe é uma metodologia que deve ser incorporada na assistência neonatal como parte integrante do tratamento dos recém-nascidos. 5

Todavia, percebe-se que não se tem levado em consideração a percepção da mãe e as dificuldades com as quais ela se depara durante a permanência no hospital.

Ao priorizar a presença junto ao filho hospitalizado, a mãe distancia-se de suas atribuições de mulher, de companheira, de trabalhadora, de filha e de mãe de outros filhos para tornar-se mãe de um recém-nascido que necessita de cuidados hospitalares, evidenciando uma situação de conflito para ela. Assim, diante da necessidade de permanecer no ambiente hospitalar, as mães passam a conviver com um novo cotidiano e se deparam com a necessidade de criar recursos para enfrentar e se adaptar à nova condição.

O presente trabalho é um recorte de um estudo mais amplo, 6 e teve como objetivo conhecer o cotidiano da mãe que permanece no alojamento materno da Unidade de Terapia Intensiva Neonatal e os recursos por elas criados para o enfrentamento da nova realidade: mãe de recém-nascido internado na Unidade de Terapia Intensiva Neonatal.

\section{Métodos}

Trata-se de uma pesquisa qualitativa, realizada por meio de um estudo descritivo-exploratório.

Ao tomar como objeto da pesquisa a permanência da mãe no alojamento materno, a metodologia foi direcionada para apreender o sentimento das mulheres-mães em relação a essa permanência.

O estudo foi realizado na Fundação de Assistência Integral à Saúde do Hospital Sofia Feldman, no distrito sanitário Norte, Belo Horizonte, Minas Gerais, Brasil, que é caracterizada como uma instituição filantrópica, não governamental, que assiste à saúde da mulher e da criança, atendendo exclusivamente à clientela do Sistema Único de Saúde (SUS). ${ }^{7}$

Para a assistência ao recém-nascido, em julho de 2000 foi inaugurada uma unidade neonatal destinada a cuidados intermediários (UCIN), com 10 leitos. Em 2001, foram acrescidos 12 leitos de UTIN e, atualmente, são 31 leitos de UTIN, 18 de UCIN, e 8 leitos de cuidado mãe-canguru. Concomitantemente ao aumento dos leitos neonatais, a instituição buscou facilitar e estimular a permanência da mãe junto ao filho, mesmo estando ele sob cuidados intensivos. Assim, foi iniciada a estruturação do alojamento materno, em 2002, destinado à permanência dessas mães. Essa unidade possui 19 leitos, possibilitando às mães condições de repouso, alimentação e acompanhamento pela equipe multiprofissional.

A coleta de dados ocorreu no período de 26 de outubro a 17 de novembro de 2005 , e teve início após autorização da instituição e aprovação da Câmara do Departamento de Pediatria e do Comitê de Ética em Pesquisa da Universidade Federal de Minas Gerais. Foi solicitada a autorização para uso de gravador, de máquina fotográfica e dos diários de campo das participantes, após a assinatura das mesmas do termo de consentimento livre e esclarecido. Para assegurar o anonimato, os nomes das participantes, dos profissionais e das instituições foram substituídos por nomes fictícios.

Foram sujeitos da pesquisa 35 mães que permaneceram no alojamento materno durante a internação do filho na UTIN no período da coleta de dados. Na observação participante todas foram incluídas e receberam o diário de campo, enquanto a participação das mães nos grupos focais foi definida pela aplicação de critérios de inclusão: no primeiro grupo - estar no alojamento materno há, no mínimo, 
três dias e, no segundo, foram considerados os critérios do grupo anterior e ainda não ter participado do primeiro.

As técnicas utilizadas para a captação da realidade empírica foram a observação participante e o grupo focal.

A observação participante permite uma aproximação do significado que os sujeitos atribuem à realidade que os cerca e às próprias ações. É a possibilidade de um contato estreito entre o pesquisador e o fenômeno pesquisado. ${ }^{8}$ A utilização da observação participante possibilita descrever uma cultura, um ambiente ou uma instituição, possibilitando gerar conhecimento sobre a vida humana, fundamentandose no dia-a-dia. 9

O grupo focal possibilita ao grupo discutir um tema sob seus diferentes aspectos e os dados são coletados a partir da fala dos participantes. Além da possibilidade de captação da realidade vivida pelos sujeitos através de seu discurso, permite a apreensão de seus sentimentos, atitudes, idéias e informações não-verbais a respeito de um determinado assunto. 10

Os instrumentos utilizados para o registro dos dados foram os diários de campo da pesquisadora e das participantes, além de gravador e fita.

Os registros no diário de campo iniciaram-se com a sua inserção no campo tendo sido realizados imediatamente após as observações. O diário de campo das participantes foi entregue a cada mulher quando ela ingressava no alojamento materno, e recolhido, quando o filho recebia alta da UTIN. Ao receber o diário de campo cada participante foi orientada a registrar as atividades que realizava a cada dia, seus sentimentos e o que mais desejasse durante sua permanência no alojamento materno.

Os dados coletados foram sistematizados e analisados conforme a técnica de análise de conteúdos. ${ }^{11}$ Essa técnica engloba várias formas de análise, de acordo com a necessidade de processar determinados aspectos do texto. No presente estudo foi utilizada a análise temática que, segundo Bardin (1977: 105): 11

[...] consiste em descobrir os núcleos de sentido que compõem a comunicação e cuja presença e freqüência de aparição podem significar alguma coisa para o objetivo analítico escolhido.

Os temas que surgiram foram agrupados por similaridade, permitindo a identificação de duas categorias empíricas com suas respectivas subcategorias: a) a condição de mãe de um filho recémnascido internado na UTIN: sentimentos vivenciados; incerteza e medo de perder o filho; culpa; fé e religiosidade; o poder do recém-nascido; b) a permanência no alojamento materno: vivência do espaço hospitalar; convivência entre as mães; demandas da mulher e da família; relações de ajuda às mães acompanhantes de recém-nascido internado na UTIN; descoberta de novos sentidos; compromisso, participação e aprendizado no cuidado com o filho. As categorias e subcategorias empíricas foram então descritas, analisadas e interpretadas.

Neste artigo, foi analisada a categoria a permanência no alojamento materno com as seguintes subcategorias: vivência do espaço hospitalar, convivência entre as mães, demandas da mulher e da família e apoio recebido.

\section{Resultados e Discussão}

\section{A vivência do espaço hospitalar}

Ao decidir permanecer no alojamento materno durante a internação do seu filho na UTIN, a mãe passa a conviver com um novo cotidiano, muitas vezes determinado pelos interesses e pela dinâmica institucional:

Você acorda já está na hora de tomar café, daqui a pouco vai tirar leite, depois olha o neném, daqui a pouco já é hora do almoço, a hora passa muito rápido. (Marta)

Considerando a necessidade e a opção da mãe de permanecer no espaço hospitalar, percebe-se que essa nova situação exige que ela se desprenda de seu cotidiano, do qual já tinha domínio, para vivenciar uma nova cotidianidade, adaptando-se a uma dinâmica delimitada pelas normas e rotinas institucionais.

Eu tenho, eu tinha mania de assistir televisão até duas horas da manhã. Lá (alojamento) a regra é até meianoite. Tem gente que dorme dez horas e a televisão incomoda. Isso é chato, entendeu? (Carla)

Durante a permanência no alojamento materno a mãe experimenta a contradição de permanecer em um ambiente organizado para possibilitar o seu conforto e bem-estar, mas que ao mesmo tempo é cenário de todo o sofrimento que ela compartilha com o filho na luta pela sobrevivência, como expressa o enunciado a seguir:

As pessoas que ficam no alojamento são muito bem acomodadas, têm direito a todas as refeições, banho, ver o bebê 24 horas, televisão, geladeira, uma cama confortável 
e acima de tudo, são todos muito atenciosos. Aqui temos todo o conforto necessário para que possamos nos sentir bem, só o que falta é felicidade, pois ela só teremos quando sairmos daqui. (Carla)

A decisão de permanecer no alojamento materno manifesta uma forte dualidade de sentimentos. A mãe se sente dividida entre atender às necessidades do filho doente, às demandas da família e às próprias necessidades.

Ao mesmo tempo em que o alojamento materno surge como um espaço onde se estabelecem relações de amizade e solidariedade também é um espaço de relações conflituosas entre as mulheres, com os profissionais de saúde e com a instituição.

Esse aspecto foi também evidenciado no estudo que buscou conhecer a experiência da mãe no ambiente hospitalar durante a internação do filho.

Segundo Reichert e Costa (2000: 56): 12

[...] a vivência no hospital é muito traumatizante, uma vez que o indivíduo não se encontra em seu hábitat. No caso da mulher, isso é o suficiente para gerar uma crise existencial que repercute sobre o ser-mãe-no-mundo. Não estando bem consigo mesma, a mulher fica vulnerável na sua relação interpessoal, porque seus sentimentos transcendem o seu querer-estar-com o outro.

A permanência, muitas vezes prolongada, no espaço hospitalar adicionada à vivência da situação de risco contínua dos filhos impede a mãe de cuidar de si própria e atender às suas necessidades como alimentação, repouso e sono, manifestando sinais evidentes de cansaço físico e mental, como expresso no discurso a seguir:

As mães mais próximas e divertidas já receberam alta, ainda resisto aqui. Não é um lugar ruim, mas difícil de relaxar, estou com o corpo todo duro e dolorido, os braços e mãos principalmente. (Júnia)

Esse foi também um achado do estudo que buscou conhecer a experiência da mãe como acompanhante do filho hospitalizado. Segundo Bezerra e Fraga, ${ }^{13}$ essa situação constitui um momento, nem sempre breve, de preocupação e sofrimento, para a mãe, que convive com o sofrimento psíquico concretizado em insônia, falta de apetite, desconforto mental e depressão.

Considerando as necessidades das mulheres e as limitações encontradas por elas para cuidar de si durante o período em que permanecem no alojamento materno, foi criado um salão de beleza na instituição. O serviço é oferecido gratuitamente tanto às mulheres que se encontram no alojamento materno, quanto às que estão internadas na maternidade devido à gravidez de risco. Funcionando duas vezes por semana, é um projeto coordenado pelo serviço de terapia ocupacional, em parceria com duas voluntárias cabeleireiras da comunidade. A criação do salão de beleza possibilitou oferecer à mulher um espaço que fosse apenas dela. Por alguns instantes elas agiam em função de seu desejo e de suas próprias necessidades, deixando de ser apenas mães para se tornarem também mulheres.

Todavia, mesmo diante de iniciativas como o salão de beleza, foram expressos os limites das atividades propostas pela equipe frente às necessidades manifestadas pelas mulheres durante a permanência no alojamento materno. Os limites foram percebidos também pelo conteúdo abordado durante os atendimentos em grupo, realizados pela equipe multiprofissional, onde a temática central era predominantemente vinculada às necessidades de cuidado do recém-nascido.

\section{A convivência entre as mulheres-mães}

A permanência no alojamento materno faz a mãe conviver com outras situações de vida além da sua, como o sofrimento de outras mulheres-mães devido à morte de seus filhos. Nessa situação, ela se identifica com o sofrimento da outra mãe, uma vez que compartilham a situação de hospitalização dos seus filhos no período neonatal.

Nesse contexto, frente à morte de outra criança, ela se depara com as incertezas quanto ao futuro do próprio filho e vive com a outra mãe e consigo, o sofrimento advindo da perda do filho, como é revelado no enunciado a seguir:

\footnotetext{
Hoje foi e está sendo um pouco difícil, pois morreu um bebê de uma mãe no alojamento. Ela chegou aqui ontem, dia 29 de outubro de 2005. O bebê dela nasceu com pneumonia e por coincidência se chamava Lucas, igual ao meu, e não tem jeito da gente não sentir também, pois estamos todas na mesma história. Chorei também. (Luciana)
}

As mães, conhecedoras da dimensão do sofrimento que as envolvem, constroem uma rede de solidariedade e amizade entre si, motivadas pelas necessidades e experiências em comum. O novo cotidiano é gerador de novas possibilidades de relacionamento e de vínculos. Elas expressaram que, no convívio diário, preocupam-se umas com as outras, e compartilham as alegrias e as tristezas, como é manifestado nos enunciados a seguir: 
No alojamento tem mulher de todos os tipos, idades. Seja ela quem for, está na mesma situação, compartilhando a mesma situação de medo, aflição, preocupação e dor. (Júnia)

E não só quando a gente tem uma notícia assim... nem tão boa em relação à criança, mas quando você também tem algum problema, todas tem um problema assim, tem mães que sofrem junto com você o seu problema, sabe... (Fabiana)

Ao mesmo tempo em que a estreita convivência entre elas favorece o estabelecimento de relações solidárias, é marcada por conflitos. Assim, as diferenças individuais e a reclusão no espaço hospitalar, acabam sendo geradoras de intrigas, brigas e tensão, como expressa o enunciado a seguir:

\footnotetext{
No começo é tudo novo, imagina você com dezenove pessoas que você nunca viu na sua frente? Então é difícil. O relacionamento em casa com mães e irmãos é difícil, imagina com quem que você nunca viu! Tem gente de vários tipos, de várias maneiras, com vários... como se diz, várias manias. (Carla)
}

Foi possível perceber que, mesmo diante das dificuldades enfrentadas na convivência no novo cotidiano, as mães permanecem no alojamento materno, convivem e buscam superar as dificuldades que se apresentam. Essa escolha é justificada pelo desejo de recuperação do filho e na prioridade de cada uma de estar junto do seu recém-nascido.

\section{As demandas da mulher e da família}

Ao decidir permanecer no alojamento materno durante a hospitalização do filho prematuro ou doente, a mãe é compelida a romper com sua cotidianidade e a se afastar dos demais membros da família. Os conflitos que emergem da nova situação, exigem delas conviver com as demandas do companheiro, dos outros filhos, dos familiares e dela própria, conforme expressa o enunciado abaixo:

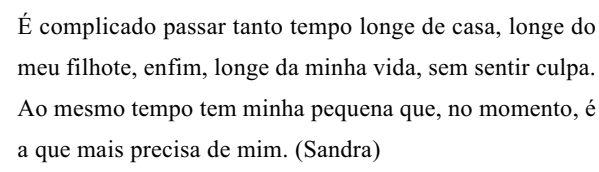

As mães ressentem-se de não poder dar assistência aos outros filhos que ficaram em casa. Os relatos delas expressam que os outros filhos se sentem preteridos e enciumados pela atenção que elas dispensam ao filho internado, e muitas vezes manifestam sentimento de abandono:

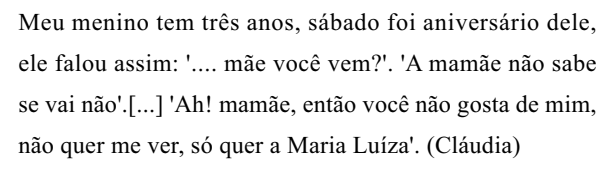

A mulher-mãe, ao priorizar a presença junto ao filho hospitalizado, experimenta sentimentos ambíguos. Se, por um lado, decide permanecer no alojamento materno, por outro, depara-se com suas próprias necessidades, anseia voltar para casa e retomar a rotina e o cotidiano que vivia antes do nascimento do filho:

\section{A vontade mesmo é de ir para casa, de volta para minha vida. (Luciana)}

Com o afastamento do convívio familiar, a mulher-mãe se sente privada das relações de carinho e afeto dos filhos e do companheiro. A saudade dos membros mais próximos da família foi um sentimento expressado com freqüência pelas mulheresmães:

Pra mim tem os dois lados [...] A gente está aqui, presente, perto do filho, sabendo o que está ocorrendo. Mas por um lado é ruim, porque a gente fica com saudade da família, sente falta, sabe... (Fabiana)

A decisão de permanecer no alojamento materno foi manifestada pelas entrevistadas como conflituosa, sendo uma constante o sentimento de estar dividida entre cuidar do recém-nascido hospitalizado ou dos demais membros da família.

Essa situação pode ser agravada quando não há a colaboração entre os familiares devido a percepções diferentes da nova situação e, portanto, não reconhecem a necessidade de a mãe permanecer no hospital cuidando do recém-nascido.

\section{As relações de ajuda às mulheres-mães acompanhantes de recém-nascidos internados na UTIN}

A nova situação e o novo cotidiano enfrentados pela mulher-mãe ao acompanhar a hospitalização do filho na UTIN, parecem favorecer a formação de uma rede de apoio. $\mathrm{O}$ apoio origina-se das redes sociais as quais a mãe pertence e das que são construídas no próprio hospital.

A permanência no alojamento materno e a convivência contínua com outras mães que enfrentam a mesma situação favorecem a construção 
de relações de ajuda. Elas confortam-se mutuamente e, mesmo diante de acontecimentos inesperados e ruins, buscam unir as forças, a esperança e a fé para enfrentar as dificuldades, como expresso no enunciado a seguir:

A convivência no alojamento a cada dia fica melhor. As colegas que estão na mesma situação se apóiam, fazem brincadeiras, descontraem o ambiente que já é muito tenso. A cada dia aprendemos uma lição de vida diferente. [...] Hoje vejo o alojamento como uma terapia constante, que ajuda a controlar a ansiedade e superar as dificuldades. Conversamos sobre tudo! As etapas do desenvolvimento dos bebês, nossa vida como mulher, a presença paterna, etc. É impressionante como os problemas são parecidos, então ficou mais fácil darmos as mãos e nos ajudarmos. (Sandra)

Nesse sentido, a análise dos discursos permite cotejar o encontrado no estudo que buscou compreender o funcionamento da dinâmica familiar da criança internada em UTI pediátrica, conforme Bousso e Angelo. 14 Tais estudos relatam que familiares que estão lidando com experiências semelhantes, desenvolvem relacionamentos significativos na sala de espera da UTI. Segundo esses autores, os familiares, ao escutarem as histórias contadas por outras famílias, refletem sobre o que estão vivenciando e se sentem mais esperançosos e fortes. Os resultados encontrados em outros estudos, 15,16 também expressam que a possibilidade de a mãe compartilhar as experiências e sentimentos decorrentes da situação de doença do filho com outras mães que se encontram em situação semelhante, configura-se como uma fonte de apoio para elas.

Outra fonte de apoio para a mulher-mãe, durante sua permanência no alojamento materno, foi a família, que se mostrou presente nos momentos difíceis e buscou atender às suas necessidades.

A interação com os profissionais de saúde emerge, também, como uma fonte de apoio para as mães. Elas valorizam as atitudes de respeito e consideração por parte da equipe e se sentem compreendidas em suas necessidades, como expressa o discurso a seguir:

A forma como vocês tratam a gente também... o jeito de

falar... tudo já ajuda a gente nesse momento nosso. (Ana)

Esse aspecto foi relatado em outros estudos, 16,17 que destacam o apoio que a mãe recebe, inclusive dos profissionais, como fundamental para que ela possa desempenhar o seu papel de acompanhante.

A participação das mães nas atividades de lazer e em outros atendimentos grupais realizados pela equipe multiprofissional possibilita que elas se distanciem da difícil situação que estão vivendo e compartilhem momentos de alegria e descontração.

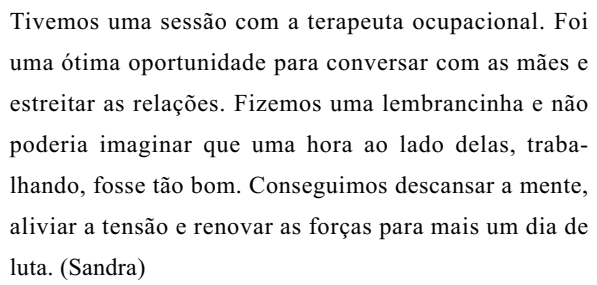

Esse achado vai ao encontro do relatado por Vasconcelos et al.,15 ao descreverem a experiência de implantação de um Grupo de Apoio à Mãe Acompanhante (GAMA) de recém-nascido prétermo e de baixo peso em um hospital do Recife, Pernambuco. Segundo aqueles autores, o GAMA modificou o significado de ser mãe acompanhante, pois favoreceu novas amizades, aconselhamentos e troca de experiências, minimizando os efeitos indesejáveis da hospitalização. Vasconcelos et al.15 recomendam a utilização de estratégias dessa natureza pelos profissionais de saúde na prática clínica, consolidando uma concepção ampliada do fazer saúde no contexto hospitalar.

\section{Considerações finais}

A importância da presença da mãe junto ao recémnascido é reconhecida por diversos autores 1,2 que a consideram fundamental para fortalecer o vínculo mãe-filho, repercutindo nas reações emocionais do filho a longo prazo. Todavia, frente à necessidade de permanecer no hospital acompanhando o filho hospitalizado, as mães mostram-se divididas entre estar junto ao filho que se encontrava em uma situação vulnerável ou preservar sua privacidade e sua cotidianidade.

Este estudo permitiu conhecer como as mulheres constroem um novo cotidiano ao decidirem permanecer no alojamento materno durante a hospitalização do filho na UTIN. As mães, mesmo distantes do lar, exigem de si próprias o cumprimento das atribuições próprias, como mãe, companheira e na organização da casa. Durante a permanência no alojamento materno, além de incorporar novos sentimentos e emoções, muitas vezes perturbadores e geradores de ansiedade, ela não se desvincula completamente de suas preocupações e atribuições como companheira, mãe de outros filhos, filha e trabalhadora. Faz-se necessária a realização 
de estudos sobre as repercussões, para a família, da ausência ou distanciamento da mulher.

O hospital surge como um espaço em que se estabelecem relações conflituosas, mas que também possibilita a construção de laços de amizade e solidariedade. Pelo exposto, foi considerado que o acompanhamento em grupo pela equipe multiprofissional, onde as mães possam expor seus sentimentos e dificuldades, mostra-se importante para o enfrentamento e a superação dos conflitos manifestados cotidianamente por elas, minimizando as tensões e facilitando a construção de acordos de convivência.

O presente estudo permitiu conhecer a singularidade do momento vivido pela mãe e identificar que a

\section{References}

1. Bowbly J. Separation anxiet. Int J Psychoanal. 1960; 41: 89113.

2. Spitz RA. O primeiro ano de vida. São Paulo: Martins Fontes; 1996.

3. Brasil. Ministério da Saúde. Estatuto da criança e do adolescente. Brasília, DF; 1991.

4. Scochi CGS. A humanização da assistência hospitalar ao bebê prematuro: bases teóricas para o cuidado de enfermagem [tese livre docência]. Ribeirão Preto: Escola de Enfermagem Materno-Infantil e Saúde Pública da Universidade de São Paulo; 2000.

5. Lamy ZC. Unidade neonatal: um espaço de conflitos e negociações [tese doutorado]. Rio de Janeiro: Instituto Fernandes Figueira da Fundação Oswaldo Cruz; 2000.

6. Dittz ES. A vivência da mulher-mãe no alojamento materno durante a internação do recém-nascido na Unidade de Terapia Intensiva Neonatal [dissertação mestrado]. Belo Horizonte: Faculdade de Medicina da Universidade Federal de Minas Gerais; 2006.

7. Madeira LM, Duarte ED. A gestão hospitalar e a integralidade da assistência: o caso do Hospital Sofia Feldman. In: Pinheiro R, Ferla AA, Mattos RA. Gestão em redes: tecendo os fios da integralidade em saúde. Rio de Janeiro: EDUSC; 2006.

8. Lüdke M, André MEDA. Pesquisa em educação: abordagens qualitativas. São Paulo: EDU; 1986.

9. Nogueira-Martins MCF, Bógus MC. Considerações sobre a metodologia qualitativa como recurso para o estudo das ações de humanização em saúde. Saúde Soc. 2004; 13: 4457.

Recebido em 1 de agosto de 2006

Versão final apresentada em 10 de setembro de 2007

Aprovado em 7 de novembro de 2007 possibilidade de conviver com outras mulheres que compartilham a mesma situação favorece a adaptação ao novo cotidiano, bem como o enfrentamento das dificuldades que se apresentam.

No que se refere ao profissional de saúde, deve ser considerada a importância de auxiliar a mãe, diante dessa nova realidade, a encontrar seu lugar no novo ambiente e no cuidado do filho. Deve-se considerar que existe uma particularidade no processo de adaptação de cada delas e que, somente uma escuta sensível e atenta, possibilitará ao profissional de saúde uma atuação efetiva e respeitosa, considerando as necessidades de cuidado de cada mãe.

10. Sena RR, Duarte ED. Contribuição para a construção do percurso metodológico do projeto de classificação internacional das práticas de enfermagem em saúde coletiva. In: Chianca TC, Antunes MJM organizadores. Classificação internacional das práticas de enfermagem em saúde coletiva. Brasília, DF: Ministério da Saúde; 1999. p. 325-33.

11. Bardin L. Análise de conteúdo. Lisboa: Edições 70; 1977.

12. Reichert APS, Costa SFG. Experiência de ser mãe de recém-nascido prematuro. João Pessoa: Idéia; 2000.

13. Bezerra LFR, Fraga MNO. Acompanhar um filho hospitalizado: compreendendo a vivência da mãe. Rev Bras Enfermagem. 1996; 49: 611-24.

14. Bousso RS, Angelo M. Buscando preservar a integridade na unidade familiar: a família vivendo a experiência de ter um filho na UTI. Rev Esc Enfermagem USP. 2001; 35: 1729.

15. Vasconcelos MGL, Leite AM, Scochi CGS. Significados atribuídos à vivência materna como acompanhante do recém-nascido pré-termo e de baixo peso. Rev Bras Saúde Matern Infant. 2006; 6: 47-57.

16. Caetano LC. Vivendo no método canguru: a tríade mãefilho-família [tese doutorado]. Ribeirão Preto: Escola de Enfermagem da Universidade de São Paulo; 2004.

17. Oliveira I. Vivenciado com o filho uma passagem difícil e reveladora - a experiência da mãe acompanhante [tese doutorado]. São Paulo: Escola de Enfermagem da Universidade de São Paulo; 1998. 